\title{
Effects of Enterprise Technology on Supply Chain Collaboration and Performance
}

\author{
Ling Li \\ Department of Information Technology and Decision Sciences \\ Old Dominion University \\ Norfolk, VA, USA
}

\begin{abstract}
Supply chain collaboration has received increasing attention from scholars and practitioners in recent years. However, our understanding of how enterprise information technology facilitates supply chain collaboration is still very limited. This paper extends the theory established in enterprise information technology and supply chain collaboration literature.
\end{abstract}

Keywords: enterprise information technology, supply chain collaboration, supply chain performance.

\section{Introduction}

Enterprise Information technology integrates business functional areas and links suppliers and customers of the entire supply chain. Today, e-solutions are a must-have weapon for a supply chain to improve collaboration to compete in the global market. Equipped with integrated information technology, many manufacturing producers have adopted the collaborative strategy on production planning, demand forecasting and inventory replenishment to provide the end user what he wants, how he wants it, and when he wants it.

This study is to investigate the effects of enterprise technology on supply chain collaboration and performance. Structural equation modeling is employed to test the multi-phased conceptual model which is shown in Figure 1. Enterprise technology assimilation is indicated using two factors: enterprise technology use for exploitation (F1) and enterprise technology use for exploration (F2). Based on the theory of organizational learning [1] [2], we define enterprise technology assimilation for exploitation as the use of technology for the execution of supply china routine processes. Similarly, enterprise technology assimilation for exploration is defined as the implementation of unstructured and strategic supply chain activities. Planning collaboration (F3) and forecasting and replenishing coordination (F4) are considered as supply chain collaboration measures. Collaboration and coordination in planning is defined as jointly plan for supply chain key activities [3] [4]; while operational collaboration and coordination are defined as information sharing to achieve efficient task execution [5]. Operational benefits (F5) are defined as first-order benefits that 


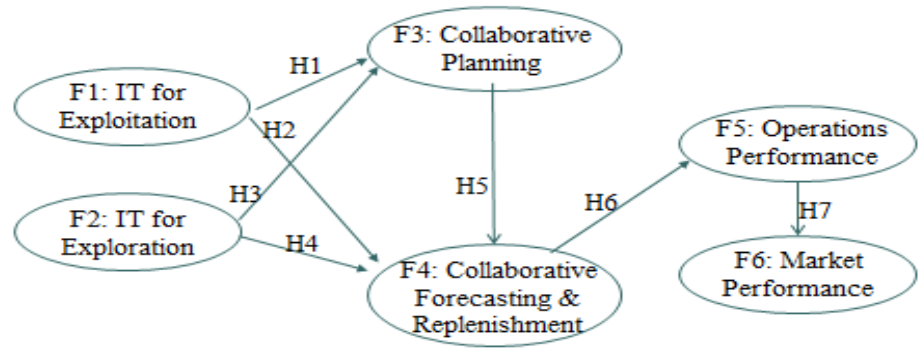

Fig. 1. Research Model

arise directly from effective supply chain collaboration. Conversely, benefits for market performance (F6) arise through better operational performance supported by supply chain collaboration [6].

\section{Background}

\subsection{Adaptive Process Concept toward Enterprise Information Technology Assimilation}

The exploitation of enterprise information technology in supply chain collaboration involves using enterprise technology to facilitate routine business practices, such as order receiving, order tracking, new accounts establishment, existing account maintenance, invoicing, material transaction, etc. These activities refine existing business patterns with benefits occurring over a short to immediate time period [7]. With enterprise technology, users are able to improve operational efficiency through measures such as increasing standardization or tightening process control. Furthermore, the exploitation approach tends to result in operational benefits such as lead time reduction and inventory accuracy [5]. Firms oriented to exploitation, use enterprise information technology for information sharing, channel collaboration, and integrated forecasting and inventory replenishment. For example, Cisco outsources more than $50 \%$ of its production capacity. Using enterprise information technology, it effectively process orders online which results in enhanced ability to rapidly respond to the demand changes in the supply chain [5].

The exploration of enterprise technology, on the other hand, diffuses beyond the organization and involves uncovering new methods to solve long-term supply chain collaboration problems. Exploration is defined by terms such as search, innovation, and discovery, with benefits occurring over a longer time horizon and beyond the organization [1] [8]. Unlike the exploitation approach that place emphasis on efficiency, consistency and process control, the exploration approach involves risk taking and experimentation. Firms oriented toward exploration of enterprise information technology develop new business models and strategies that enable them to expand new markets and develop new products [8]. For example, relied on enterprise technology to share business information with vendors and customers, Dell 
Computer has gained market share by building customized computers using the Internet as an order fulfillment vehicle. Dell assembles computers but outsources most of the parts and components it needs for production. Outsourcing has made collaborative planning, forecasting, and replenishment a vital vehicle to implementing mass customization strategy in supply chain.

\subsection{Enterprise Technology and Supply Chain Collaboration}

A supply chain is as strong as its weakest link. The notion here focuses on strong and effective collaboration. The fundamental point that distinguishes supply chain management and traditional materials management is how the collaboration of trading partners is managed. Thus, collaboration is a most talked about issue in today's global supply chain management. In recent years, retailers have initiated collaborative agreements with their supply chain partners to establish on-going planning, forecasting, and replenishment process. This initiative is called collaborative planning, forecasting, and replenishment (CPFR). The Association for Operations Management defines CPFR as follows:

"Collaboration process whereby supply chain trading partners can jointly plan key supply chain activities from production and delivery of raw materials to production and delivery of final products to end customers" - The Association for Operations Management ${ }^{l}$.

The enabler of CPFR is information technology. The earlier versions of CPFR are Electronic Data Interchange (EDI), bar coding, and vendor-managed inventory (VIM). The more current version of CPFR takes advantage of enterprise information technology. For example, Wal-Mart has engaged in CPFR with about 600 trading partners [9]. The use of enterprise technology has permitted strong supply chain coordination for production planning, demand forecasting, order fulfillment, and customer relationship management. Published studies have consistently support the effective result through association between enterprise technology use and organizational coordination [3] [5].

Supply chain collaboration has been referred to as the driving force of effective supply chain management [10] [11]. The objective of supply chain collaboration is to improve demand forecast and inventory management, with the right product delivered at right time to the right location, with reduced inventories, avoidance of stock-outs, and improved customer service. The value of supply chain collaboration lies in the broad exchange of planning, forecasting and inventory information to improve information accuracy when both the buyer and seller collaborate through joint knowledge of sales, promotions, and relevant supply and demand information.

Supply chain collaboration becomes a core competence in a global market. There are eye-opening collaborative results in forecasting and inventory management.

\footnotetext{
${ }^{1}$ The Association for Operations Management is formerly known as American Production and Inventory Control Society (APICS).
} 
Nabisco and Wegmans, for example, noted over a 50\% increase in category sales. Wal-Mart and Sara Lee reported a 14\% reduction in store-level inventory with a $32 \%$ increase in sales. Nevertheless, integrating disconnected planning and forecasting activities in the entire supply chain is still a challenge. It has been reported that supply chain collaboration has proved difficult to implement; it is difficult to understand when and with whom to collaborate; it has relied too much on information technology and there is a lack of trust between trading partners [10].

Given the literature and anecdotal evidence, we may conclude that supply chain collaboration has great potential in supply chain management, but further investigation is needed to understand its practical value. As such, we hypothesize the following:

Hypothesis 1: The higher the level of enterprise information technology use for exploitation the greater the supply chain perceived level of collaborative planning.

Hypothesis 2: The higher the level of enterprise information technology use for exploitation the greater the supply chain perceived level of collaborative forecasting and replenishment.

Hypothesis 3: The higher the level of enterprise information technology use for exploration the greater the supply chain perceived level of collaborative planning.

Hypothesis 4: The higher the level of enterprise information technology use for exploration the greater the supply chain perceived level of collaborative forecasting and replenishment.

The VICS Working Group conceptualized a sequential collaborative process [12]. The process has nine steps which are divided into three phases. The first is planning phase, which consists of steps 1 and 2, and creates the collaborative front-end agreement and joint business plan. The second is the forecasting phase, including steps 3-8, and the last is the replenishment phase (step 9). Specifically, a sequential process is introduced. The second and third phases execute supply chain orders which are translated from the joint business plan which is determined at the first phase [4].

The importance of collaborative has been well documented. For example, in the spring of 2001, Sears and Michelin (a French company) began discussions on collaborative planning. Later that year, their joint plan detailed a collaborative forecasting and replenishment agreement. As the result of collaboration, the combined Michelin and Sears inventory levels were reduced by 25 percent [13]. This supports our following hypothesis.

Hypothesis 5: The higher the level of collaborative planning the better the execution of collaborative forecasting and replenishment.

\subsection{The Relationship between Supply Chain Collaboration and Performance}

Research consistently supports the idea that collaboration in supply chain improves firm's operational performance and market competitiveness [6]. Companies that are able to establish collaborative relationship with their supply chain partners will have a 
significant competitive edge over their competitors. Industry practices have provided numerous examples. Mayo audio-video franchise store in Shanghai applied enterprise technology to support its collaborative planning, forecasting and replenishment activities and achieved better operational performance such as cost reduction and better market performance such as market share growth [14]. Dell Computer implements a "direct model" which builds customized computers based on customer orders. It collaborates with many of its suppliers and applies the Internet-based enterprise technology. The exploitation of enterprise technology enables Dell to implement JIT-based production system; while the exploration of enterprise technology enables Dell to develop innovative business model which opens up new markets for it. This leads us to the next two hypotheses.

Hypothesis 6: Collaborative planning, forecasting and replenishment in supply chain will directly benefit a firm's operations performance.

Hypothesis 7: Better operations performance will contribute to supply chain market performance.

\section{Research Methodology}

\subsection{Data and Constructs}

The research instrument was based upon the existing literature and pre-tested by a group of practicing managers in China, who had enterprise information technology implementation experience and supply chain collaboration knowledge. The instrument was then revised according to the suggestions from the managers. The revised questionnaire was sent in year 2006 to a group of 1000 manufacturing firms. Our effective sample size for this analysis is 177 .

Six constructs based on Figure 1 are used to test the hypotheses. Among them, two constructs are used for enterprise information technology assimilation: enterprise information technology for exploitation (EIT) and enterprise information technology use for exploration (ERT). Based on March's discussion of organizational learning theory [1] and published studies on enterprise technology use [15], we define enterprise technology use for exploitation as the use of EIT for production scheduling, material requirement, the implementation of structured inter-firm processes such as order processing and order shipment facilitation. These items are measured on a seven-point Likert scale, ranging from not important (1) to absolutely critical (7).

Given the wide variation in definitions and usage of the concept in the literature, the collaborative activities suggested in this study are just one of many ways that can be applied to capture the overall thrust of supply chain collaboration through technology implementation. In this study, supply chain collaboration is measured by two constructs; one deals with collaborative planning (CP) and the other collaborative forecasting and replenishment (FR). We structure collaborative activities to two constructs because one is at the planning level and the other at the operational level [4]. A number of authors suggest that collaborative planning processes such as joint 
decision-making and planning precede operational collaboration such as demand forecasting and inventory replenishment [3]. The collaboration constructs are also assessed on a seven-point Likert scale, ranging from significantly lower (1) to significantly higher (7) as compare to their previous supply chain activities.

The operational performance construct $(\mathrm{OP})$ is based on the published operations management literature [5] [15]. Inventory represents the material flow in supply chain and is the physical item that the suppliers send to its customers. The focus is placed on inventory accuracy, safety stock reduction, delivery lead time and order fulfillment lead time [15]. Operations performance items are measured from "not improved (1)" to "significantly improved (7)."

The market performance construct has empirical support. The most commonly cited financial performance indicators are market share growth, economic growth opportunity, and customer retention [13]. The performance items are measured on a 7point Likert scale, ranging from significantly lower (1) to significantly higher (7) as compared to the firm's pre-implementation performance.

Structural equation model is employed to test the hypothesized relations among six constructs. Structural equation modeling measures multiple relationships between independent and dependent variables, thus accommodating aggregated dependent relationships simultaneously in one comprehensive model.

\subsection{Construct Measure and Reliability}

Our conceptual model involves relationships among six constructs. In this section, we provide evidence that the measurement of these constructs has been effective in terms of reliability and validity. All of the survey items that were used for measurement of the constructs are listed in Table 1. Empirical support for effective measurement is provided by a Cronbach Alpha. Enterprise technology for exploitation was measured using three items. The reliability for the scale is 0.81 (Table 1). Enterprise technology for exploration was measured using a three times. The reliability is 0.817 (Table 1). The reliabilities for collaborative planning and collaborative forecasting and replenishment are 0.756 and 0.868 respectively. Finally, the reliabilities for operational performance and market performance are 0.805 and 0.804 respectively.

\section{Results}

\subsection{Structural Model Test Result}

The results of the structural model tested evaluating overall model fit are shown in Fig. 2. Additionally, chisquare/df is 1.06 , GFI is .916, AGFI is.890, CFI is .993, and RMSEA < .018; all meet the acceptable threshold. The standardized path coefficients are significant at p-value of $p<0.01$ (Table 1). Combining the findings of fit indices obtained from the measurement model and the structural model, we can see that the sample data support our conceptual model. The following section presents the outcomes of hypotheses associated with the structural model. 


\subsection{Findings Related to Hypotheses}

We further investigated the findings related to specific hypothesis and individual paths of the model. The set of four hypotheses relate to enterprise technology and supply chain collaboration is examined first.

Hypothesis 1 is not significant.

Hypothesis 2 is supported at $\mathrm{p}<0.10\left(\gamma_{1}=0.157\right)$.

Hypothesis 3 is supported at $\mathrm{p}<0.01\left(\gamma_{2}=0.462\right)$.

Hypothesis 4 is supported at $\mathrm{p}<0.01\left(\gamma_{3}=0.257\right)$.

This set of findings reveals some valuable insights on how enterprise technologies facilitate supply chain collaboration. The result suggests that applying enterprise technology for exploitation directly affects operational collaboration such as demand forecasting and inventory replenishment. However, it does not have a significant impact on collaborative planning. Furthermore, applying enterprise technology for exploration, which focuses on identifying the trends in sales and operations management and leveraging firm's expertise to create new markets and production, has direct positive effect on both collaborative planning and collaborative forecasting and replenishment. The results from this study underscore the complexity of the construct of enterprise technology exploitation and indicate that exploration may have an overarching impact on supply chain collaboration. These findings suggest that enterprise technology use creates a unique and specific value to collaborations within supply chain.

Next, we look at the hypothesis that relates the collaborative planning construct to collaborative forecasting and replenishment.

Hypothesis 5 is supported at $\mathrm{p}<0.01\left(\beta_{1}=0.3901\right)$.

The finding provides support for the sequential process of collaborative planning and collaborative operational activities. A possible explanation is that sharing information through enterprise technology and making collaborative plans are not enough to improve operations performance. In order to achieve better inventory and lead time performance, supply chain managers have to be able to get involved with the complexity of collaborative planning with multiple echelons in a supply chain and implement the plan through demand forecast and inventory management. This finding is consistent with the result obtained by Disney et al. [16].

Finally, we examined the hypotheses that relate supply chain collaboration to operations and market performance.

Hypothesis 6 is supported at $\mathrm{p}<0.01\left(\beta_{2}=0.2842\right)$.

Hypothesis 7 is supported at $\mathrm{p}<0.01\left(\beta_{3}=0.6189\right)$. 
Table 1. Scales and Constructs

\begin{tabular}{|l|l|c|c|c|}
\hline & & $\begin{array}{c}\text { Standard } \\
\text { coefficient }\end{array}$ & $t$-value & $\begin{array}{c}\text { Cronbach } \\
\text { alpha }\end{array}$ \\
\hline EIT1 & Use ET to schedule production and plan material requirement & 0.625 & 8.54 & 0.81 \\
\hline EIT2 & $\begin{array}{l}\text { Use ET to process order and invoices, and establish new } \\
\text { accounts }\end{array}$ & 1.015 & 14.61 & \\
\hline EIT3 & Use ET to share delivery information and facilitate shipments & 0.697 & 9.95 & \\
\hline ERT1 & Understand trends in sales \& operations management & 0.801 & 11.74 & 0.817 \\
\hline ERT2 & Integrate production design and manufacturing functions & 0.861 & 12.89 & \\
\hline ERT3 & $\begin{array}{l}\text { Leverage firm's expertise to create new business } \\
\text { opportunities }\end{array}$ & 0.674 & 9.44 & \\
\hline CP1 & $\begin{array}{l}\text { Production planning information and data are shared with } \\
\text { channel members }\end{array}$ & 0.346 & 4.24 & 0.756 \\
\hline CP2 & $\begin{array}{l}\text { The channel managers communicate on overall business } \\
\text { decisions }\end{array}$ & 0.725 & 9.84 & \\
\hline CP3 & $\begin{array}{l}\text { Planning for new markets and products with channel } \\
\text { members }\end{array}$ & 0.573 & 7.45 & \\
\hline CP4 & Production \& capacity are jointly planned & 0.799 & 11.03 & \\
\hline FR1 & $\begin{array}{l}\text { Sales forecasting \& demand mgt are developed through } \\
\text { supply chain coordination }\end{array}$ & 0.753 & 11.02 & 0.868 \\
\hline FR2 & Inventory level information is shared within the supply chain & 0.757 & 11.09 & \\
\hline FR3 & $\begin{array}{l}\text { Delivery schedule and responsibilities are detailed in } \\
\text { contracts }\end{array}$ & 0.807 & 12.13 & \\
\hline FR4 & Channel-wide available-to-promise system is implemented & 0.710 & 10.17 & \\
\hline OP1 & $\begin{array}{l}\text { Inventory performance has improved, safety stock and stock } \\
\text { out has reduced due to collaboration }\end{array}$ & 0.766 & 10.47 & 0.805 \\
\hline OP2 & Lead time has reduced due to supply chain collaboration & 0.851 & 11.73 & \\
\hline MP1 & Created new products and new markets & 0.765 & 10.99 & 0.804 \\
\hline MP2 & $\begin{array}{l}\text { Learned new economic growth opportunity and developed } \\
\text { new business opportunities }\end{array}$ & 0.803 & 11.71 & \\
\hline MP3 & Improved customer retaining and attracted new customers & 0.720 & 10.17 & \\
\hline
\end{tabular}

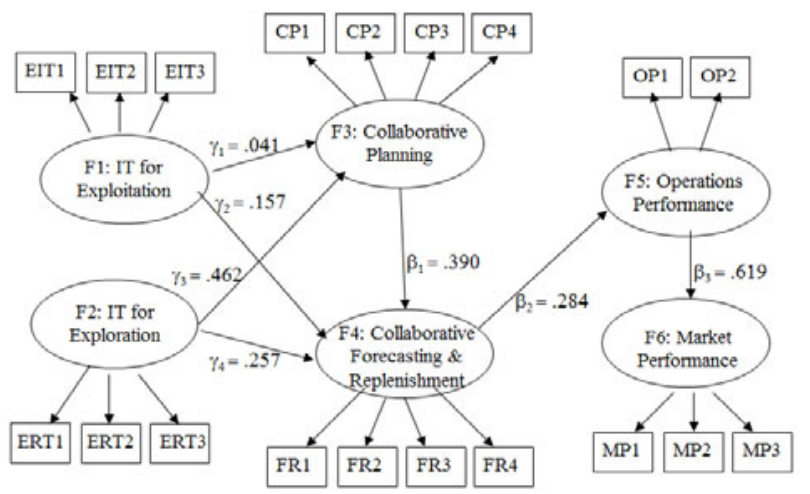

Fig. 2. Covariance Structure Model 
The findings suggest that collaborative forecasting and replenishment will significantly benefit operational performance. Better operations performance is found to have a significant impact on firm's market performance.

In summary, six of seven hypotheses have been supported by the results of the statistical analysis using data from 177 Chinese firms. Examining the results, some tentative conclusions can be made. First, enterprise information technology implementation significantly affects collaborative planning, forecasting, and inventory replenishment in a supply chain. Second, supply chain collaboration benefits firm's operational performance. Finally, market competitiveness is influenced by operations performance.

\section{Conclusions}

The study considers how collaborative activities mediate the association between enterprise information technology assimilation and market performance in supply chain. We draw upon an empirical research from 177 companies to illustrate what collaborative activities will enable supply chain to achieve better operational and market performance, given their particular enterprise information technology implementation circumstances. We have provided three major contributions in this study: (i) uncovered importance of leveraging enterprise information technology use through supply chain collaboration; (ii) identified the relationship between enterprise ownership and enterprise technology use and supply chain collaboration; and (iii) illustrated the association between collaborative activities, operational benefits, and supply chain market performance. The result of the study indicates that assisted with advanced information technology, successful collaboration among trading partners does affect firm's operational and market performance if effective communication in the process of supply chain coordination is fostered.

There are a number of avenues this research can be extended to. For example, further research on collaboration of supply chain may include risk assessment of collaboration, optimal point of product-differentiation in a supply chain, selection of trading partners, the effects vertical collaboration, horizontal collaboration, and spatial collaboration on performance.

\section{References}

1. March, J.G.: Exploration and exploitation in organizational learning. Organization Science 2(1), 71-87 (1991)

2. Subramani, M.: How do suppliers benefit from information technology use in supply chain relationships? MIS Quarterly 28(1), 45-73 (2004)

3. VICS, CPFR Guidelines. Voluntary Inter-industry Commerce Standards (2000), http: / / www. cpfr.org

4. Danes, P., Romano, P., Vinelli, A.: Managing business processes across supply networks: the role of coordination mechanisms. Journal of Purchasing and Supply Management 10(4-5), 165-177 (2004) 
5. Zhou, H., Benton, W.C.: Supply chain practice and information sharing. Journal of Operations Management 25, 1348-1365 (2007)

6. Li, L.: Assessing Intermediate Infrastructural Manufacturing Decisions that Affect a Firm's Market Performance. International Journal of Production Research 43(12), 25372552 (2005)

7. Tokman, M.: Exploration, exploitation and satisfaction in supply chain portfolio strategy. Journal of Business Logistics 28(1), 25-56 (2007)

8. Debenham, J., Wilkinson, I.: Exploitation and exploration in market competition. Industry and Innovation 13(3), 263-289 (2006)

9. Cutler, D.: CPFR: Time for the breakthrough. Supply Chain Management Review, 54-60 (May/June 2003)

10. Barratt, M.: Understanding the meaning of collaboration in the supply chain. Supply Chain Management: An International Journal 9(1), 30-42 (2004)

11. Li, L., Su, Q., Chen, X.: Ensuring Supply Chain Quality Performance through Applying SCOR Model. International Journal of Production Research 49(1), 33-57 (2011)

12. Seifert, D.(ed): Collaborative Planning, Forecasting, and Replenishment: How to Create a Supply Chain Advantage, AMACOM, pp. 27-40, 173-176. American Management Association, USA (2003)

13. Steermann, H.: A practical look at CPFR: the Sears - Michelin experience. Supply Chain Management Review, 46-53 (July/August 2003)

14. Wang, W., Guan, J., Yuan, Y., Chan, L.: CPFR and Its Application in Shanghai Maya (2004), http: / /www . pacis-net.org

15. Kelle, P., Akbulut, A.: The role of ERP tools in supply chain information sharing, cooperation, and cost optimization. International Journal of Production Economics 93-94, 41-52 (2005)

16. Disney, S.M., Naim, M.M., Potter, A.: Assessing the impact of e-business on supply chain dynamics. International Journal of Production Research 89, 109-118 (2004) 